\title{
Trietilamin varlığında bazı alifatik karboksilik asitlerden disübstitüe organosiklotrifosfazenlerin sentezi ve karakterizasyonu
}

\author{
Orhan PAMUKÇU, Fatih ASLAN* \\ Harran Üniversitesi, Fen-Edebiyat Fakültesi, Kimya Bölümü, Şanlıurfa \\ Geliş Tarihi (Received Date): 30.01 .2020 \\ Kabul Tarihi (Accepted Date): 01.05.2020
}

$\ddot{O} z$

Organosiklotrifosfazen elde etmek için bazı alifatik karboksilik asitler ile hekzaklorosiklotrifosfazenin tepkimesi trietilamin varlığında THF çözücüsünde gerçekleş̧irildi. Asetik asit, bütirik asit, 4-kloro-sinnamik asit ve 4-kloro-fenil-asetik asit tepkimelerde alifatik karboksilik asit olarak kullanıldı. Bütün tepkimelerde oluşan trietilamonyum klorür miktarl, yer değiş̧tiren iki mol klora karşıllk geldiği belirlendi. Ayrıca, 18 ppm civarında ikili ve -12 ppm civarında üçlü iki pik bütün bileşiklerin (2-5) ${ }^{3 i} P$ NMR spektrumlarında görüldü. Elde edilen bu iki sonuca göre, sentezlenen organosiklotrifosfazenlerin gem-disubstitüe yapısinda olduğu belirlendi. Bütün bileşiklerin yapıları gravmetrik ve spektroskopik yöntemlerle belirlendi. IR ve NMR ${ }^{l} \mathrm{H}$, $\left.{ }^{13} \mathrm{C} v{ }^{31} \mathrm{P}\right)$ spektroskopileri bileşiklerin spektroskopik analizinde kullanıldl.

Anahtar kelimeler: Fosfazen, organofosfazen, karboksilik asit.

\section{Synthesis and characterization of disubstituted organocyclotriphosphazenes from some aliphatic carboxylic acids in the presence of triethylamine}

\begin{abstract}
The reaction of hexachlorocyclotriphosphazene with some aliphatic carboxylic acids was performed in THF solvent in the presence of triethylamine to obtain organocyclotriphosphazene. Acetic acid, butyric acid, 4-chloro-sinnamic acid and 4chloro-phenyl-acetic acid were used as aliphatic carboxylic acid in the reactions. It was
\end{abstract}

Orhan PAMUKÇU, orhan_pamukci@mynet.com, https://orcid.org/0000-0001-9314-7113

*Fatih ASLAN, faslan33@yahoo.com, https://orcid.org/0000-0001-9009-399X 
determined that the amount of triethylammonium chloride generated in all reactions corresponds to two equivalent of chlorine displaced. Additionally, two peaks were seen at around $18 \mathrm{ppm}$ as doublet and around $-12 \mathrm{ppm}$ as triplet in the ${ }^{31} \mathrm{P}$ NMR spectra of the compounds (2-5). According to these two results, the synthesized organocyclotriphosphazene derivatives were determined to be in the gem-disubstituted structure. The structures of all compounds were determined by gravimetric and spectroscopic methods. FTIR and NMR $\left({ }^{1} \mathrm{H},{ }^{13} \mathrm{C}\right.$ and $\left.{ }^{31} \mathrm{P}\right)$ spectroscopies were used in spectroscopic analysis of the compounds.

Keywords: Phosphazene, organophosphazene, carboxylic acid.

\section{Giriș}

Fosfazen kimyasında en fazla çalışma yapılan iki fosfazen bileşiğinden birisi de oda şartlarında kararlı olan ve çok iyi yer değiştirme tepkimesi veren hekzaklorosiklotrifosfazendir. Çok sayıda organosiklotrifosfazen, bu fosfazen ile nükleofilik özellik gösteren alkol, fenol, amin, tiyol, Grginard ve organolityum bileşiklerin tepkimelerinden türetilmiştir [1-3]. Fakat, bugüne kadar hekzaklorosiklotrifosfazen ile karboksilik asitlerin tepkimelerine ait birkaç çalışma yapılmasına rağmen, bu çalışmalarda karboksilik asitlerin bağlandığ organosiklotrifosfazenler oluştuğu belirlenememiştir [4]. Dolayısıyla, şuan karboksilik asitlerden elde edilmiş organosiklotrifosfazenler hakkında spektroskopik, kimyasal, fiziksel ve biyolojik hiçbir bilgi mevcut değildir.

Literatürdeki çalışmalar incelendiğinde, hekzaklorosiklotrifosfazen ile karboksilik asitlerin tepkimelerine ait çalışmalar 1960 ile 1975 yılları arasında gerçekleştirilmiştir [57]. $\mathrm{Bu}$ çalışmaların tamamında bu tür tepkimelerde karboksilik asitlerin fosfazen halkasına bağlanmasıyla oluşan organosiklotrifosfazenin oluşmadığı tespit edilmiştir. Bu tepkimelerde karboksilik asidin nitrili ve anhidridinin ve trisodyummetafosfat olduğu düşünülen bir fosfor bileşiğinin oluştuğu tespit edilmiştir. Hatta, bu tür tepkimler, fosfazen halkasını kıran tepkime olarak bilinmektedir. Bu yıllardan sonra da başkaca bir çalışma gerçekleştirilmemiştir. Bazı araştırmacılar karboksilik asitlerin tuzlarını bazı araștırmacılarda trietilamin baz varlığında karboksilik asitleri bu çalışmalarda kullanmıştır. Dolayısıyla, fenollerden organosiklotrifosfazen sentez yöntemindeki gibi iki farklı yöntem bu tür tepkimelerde de kullanılmıştır. Daha sonraki yıllarda, biri karboksilik asit olan iki fonksiyonel grup taşıyan organik yapılar ile hekzaklorosiklotrifosfazenin tepkimelerinden organosiklotrifosfazen sentezinde, organik yapıdaki karboksilik asit ilk önce estere dönüştürüldükten sonra tepkime gerçekleştirilmiştir [8].

Bu çalışmamızda, hekzaklorosiklotrifosfazen ile asetik asit, bütrik asit, 4-kloro-sinnamik asit ve 4-klor-fenil-asetik asidin tepkimeleri THF çözücüsünde baz olarak trietilamin varlığında gerçekleştirildi. Tepkimelerin tamamında gem-disubstieü olan 2,2di(asetoiloksi)-4,4,6,6-tetraklorosiklotrifsofazen, $\quad$ 2,2-di(bütiroiloksi)-4,4,6,6tetraklorosiklotrifsofazen,

2,2-di(4-kloro-sinnamoiloksi)-4,4,6,6tetraklorosiklotrifsofazen ve 2,2-di(4-kloro-fenil-asetoiloksi)-4,4,6,6tetraklorosiklotrifsofazen bileşiklerin oluştuğu gravmetrik ve spektroskopik yöntemlerle belirlendi. 


\section{Deneysel çalışmalar}

\subsection{Malzemeler ve kullanilan cihazlar}

Tepkimelerde kullanılan hekzaklorosiklotrifosfazen, asetik asit, bütirik asit, 4-klorosinnamik asit, 4-kloro-fenil-asetik asit ve trietilamin satın alındı ve saflaştırma işlemi yapılmadan kullanıldı. THF, aseton, diklorometan ve n-hekzan çözücüleri alındığı gibi kullanıldı. Silica jel F254 ince tabaka ve silica jel kolon dolgu maddesi saflaştırma işleminde kullanıldı.

Bileşiklerin yapısının belirlenmesinde gravmetrik ve spektroksopik yöntemler kullanıldı. Gravmetrik yöntem tepkimede oluşan trietilamonyum klorür tuzunun miktarının belirlenmesinde kullanıld1. Spektroskopik yöntemde NMR $\left({ }^{1} \mathrm{H},{ }^{31} \mathrm{P},{ }^{13} \mathrm{C}\right)$ ve FTIR spektroskopisleri kullanıldı. Bileşiklerin NMR spektrumları DMSO-D çözücüsünde gerçekleştirildi. FTIR spektrumu ATR li Shimadzu mini cihazı kullanıldı.

\subsection{Yöntem}

\subsubsection{Hekzaklorosiklotrifosfazen ile asetik asidin tepkimesi}

Hekzaklorosiklotrifosfazenin $(0,25 \mathrm{~g} ; 0,730 \mathrm{mmol})$ ve trietilaminin $(1,25 \mathrm{~mL} ; 8,755$ mmol) THF(30 mL) deki çözeltisine asetik asidin $(1,88 \mathrm{~g} ; 8,755 \mathrm{mmol}) 5 \mathrm{~mL}$ THF çözeltisi yavaş yavaş ilave edildi. Tepkime oda şartlarında 72 saat devam ettirildikten sonra oluşan tuz süzülerek ayrıldı. Oluşan tuz oda şartlarında kurutuldu ve bu tuzun 1,95 g (teorik olarak iki mol klora karş1lık trietiamonyum klorür miktarı:0,198 g) olduğu belirlendi. Çözeltideki karışım $\mathrm{CH}_{2} \mathrm{Cl}_{2} / \mathrm{n}$-hekzan(7/1) çözücü karışımında ince tabaka ve kolon kromatografileriyle saflaştırıldı. Saflaştırma işleminden sonra elde edilen beyaz kat1 bileşiğin 2,2-di-(asetoiloksi)-4,4,6,6-tetra-kloro-siklotrifosfazen(2) olduğu analiz sonuçlarında anlaşıldı (\%10, e.n.: $\left.85{ }^{\circ} \mathrm{C}\right)$. FTIR $\left(\mathrm{cm}^{-1}\right): 1760$ ve 1724 (sim. ve asim. $\mathrm{C}=\mathrm{O}), 1240,1210,1163,1136(\mathrm{P}=\mathrm{N}), 1012(\mathrm{P}-\mathrm{OCO}), 864(\mathrm{P}=\mathrm{N}-\mathrm{P}), 571$ ve $517(\mathrm{P}-\mathrm{Cl}) .{ }^{1} \mathrm{H}$ $\mathrm{NMR}\left(\left(\mathrm{CD}_{3}\right)_{2} \mathrm{CO}\right) ; \delta(\mathrm{ppm}): 1,98$ (ikil, $\left.-\mathrm{CH}_{3}\right), 3,40$ (DMSO içinde $\left.\mathbf{H}_{2} \mathrm{O}\right), 2.50$ (DMSO $\left.\mathrm{CH}_{3}\right) .{ }^{13} \mathrm{C} \mathrm{NMR}\left(\left(\mathrm{CD}_{3}\right)_{2} \mathrm{CO}\right) ; \delta$ (ppm): 167,4 (sim. ve asim. $\mathrm{C}=0$ ), 22,85 (ikili, $\left.\mathrm{CH}_{3}\right), 40$ (DMSO). ${ }^{31} \mathrm{P}$ NMR $\left(\left(\mathrm{CD}_{3}\right)_{2} \mathrm{CO} ; \mathrm{A}_{2} \mathrm{X}\right.$ spin sistemi):1,7 (ikili, $\left.\mathrm{PCl}_{2}\right),-16,50$ (üçlü, $\left.\mathrm{P}\left(\mathrm{OOCCH}_{3}\right)_{2}\right)$.

\subsubsection{Hekzaklorosiklotrifosfazen ile bütirik asidin tepkimesi}

Hekzaklorosiklotrifosfazenin $(0,25 \mathrm{~g} ; 0,730 \mathrm{mmol})$ ve trietilaminin $(1,25 \mathrm{~mL} ; 8,755$ mmol) THF(30 mL) deki çözeltisine bütirik asidin (1,88 g; 8,755 mmol) $5 \mathrm{~mL}$ THF çözeltisi yavaş yavaş ilave edildi. Tepkime oda şartlarında 72 saat devam ettirildikten sonra oluşan tuz süzülerek ayrıldı. Oluşan tuz oda şartlarında kurutuldu ve bu tuzun 1,96 g (teorik olarak iki mol klora karş1lık trietiamonyum klorür miktarı:0,198 g) olduğu belirlendi. Çözeltideki karışım $\mathrm{CH}_{2} \mathrm{Cl}_{2} / \mathrm{n}$-hekzan(7/1) çözücü karışımında ince tabaka ve kolon kromatografileriyle saflaştırıldı. Saflaştırma işleminden sonra elde edilen beyaz katı bileşiğin 2,2-di-(bütiroiloksi)-4,4,6,6-tetra-kloro-siklotrifosfazen(3) olduğu analiz sonuçlarında analaşıldı (\%10, e.n.: $\left.117{ }^{\circ} \mathrm{C}\right)$. FTIR $\left(\mathrm{cm}^{-1}\right)$ : 1753 ve 1705 (sim. ve asim $\mathrm{C}=\mathrm{O}), 1232,1175,1125(\mathrm{P}=\mathrm{N}), 1037(\mathrm{P}-\mathrm{OCO}), 857(\mathrm{P}=\mathrm{N}-\mathrm{P}), 579$ ve $518(\mathrm{P}-\mathrm{Cl}) .{ }^{1} \mathrm{H}$ NMR(DMSO; $\delta$ (ppm):2,28 (üçlü, - $\mathrm{CH}_{2}$ ), 1,58 (dörtlü, $-\mathrm{CH}_{2-}$ ), 0,92 (üçlü, $-\mathrm{CH}_{3}$ ), 2,86 (DMSO içinde $\mathrm{H}_{2} \mathrm{O}$ ), 2.05 (DMSO $\left.\mathrm{CH}_{3}\right) .{ }^{13} \mathrm{C}$ NMR(DMSO; $\delta$ (ppm): 170,69 (ikili, sim. ve asim. $\mathrm{C}=\mathrm{O}), 37,04,1783,12,80,29,10$ (DMSO). ${ }^{31} \mathrm{P} \mathrm{NMR}\left(\left(\mathrm{CD}_{3}\right)_{2} \mathrm{CO} ; \mathrm{A}_{2} \mathrm{X}\right.$ spin sistemi):18,80 (ikili, $\mathrm{PCl}_{2}$ ), -13,50(üçlü, $\left.\mathrm{P}\left(\mathrm{OOCC}_{3} \mathrm{H}_{7}\right)_{2}\right)$. 


\subsubsection{Hekzaklorosiklotrifosfazen ile 4-kloro-sinnamik asidin tepkimesi}

Hekzaklorosiklotrifosfazenin $(0,25 \mathrm{~g} ; 0,730 \mathrm{mmol})$ ve trietilaminin $(1,25 \mathrm{~mL} ; 8,755$ mmol) THF(30 mL) deki çözeltisine 4-kloro-sinnamik asidin (1,88 g; 8,755 mmol) $5 \mathrm{~mL}$ THF çözeltisi yavaş yavaş ilave edildi. Tepkime oda şartlarında 72 saat devam ettirildikten sonra oluşan tuz süzülerek ayrıldı. Oluşan tuz oda şartlarında kurutuldu bu tuzun 1,99 g (teorik olarak iki mol klora karşıllk trietiamonyum klorür miktarı:0,198 g) olduğu belirlendi. Çözeltideki karışım $\mathrm{CH}_{2} \mathrm{Cl}_{2} /$ n-hekzan(7/1) çözücü karışımında ince tabaka ve kolon kromatografileriyle saflaştırıldı. Saflaştırma işleminden sonra elde edilen beyaz kat1 bileşiğin 2,2-di-(4-kloro-sinnamoiloksi)-4,4,6,6-tetra-klorosiklotrifosfazen(4) olduğu analiz sonuçlarında analaşıldı $\left(\% 10\right.$, e.n.: $\left.147{ }^{\circ} \mathrm{C}\right)$. FTIR $\left(\mathrm{cm}^{-}\right.$ $\left.{ }^{1}\right)$ : 1754, 1728, 1704 ve 1684 ( $\operatorname{sim}$. ve asim $\left.\mathrm{C}=\mathrm{O}\right), 1247,1221,1176,1134(\mathrm{P}=\mathrm{N}), 1012(\mathrm{P}-$ OCO), 855(P=N-P), 577 ve 514 (P-Cl). ${ }^{1} \mathrm{H}$ NMR(DMSO-D); 8, 25 ve 8,15 (ikili, Aril H), 7,93 ve 7,87 (ikili, Aril H), 7,19 ve 6,93 (ikili, Alken $\mathrm{H}$ ), 3,25 (DMSO içinde $\mathbf{H}_{2} \mathrm{O}$ ), 2.40 $\left(\mathrm{DMSO}-\mathrm{CH}_{3}\right) .{ }^{13} \mathrm{C} \mathrm{NMR}\left(\left(\mathrm{CD}_{3}\right)_{2} \mathrm{CO}\right) ; \delta(\mathrm{ppm}): 168(\mathrm{C}=\mathrm{O}), 144,5$ (Aril C), 135,0 (Aril C), 133,80 (aril C), 132,5 (aril C), 131,5 (alken C), 129,5 (aleken C), 122 (Aril C), 40 (DMSO). ${ }^{31} \mathrm{P}$ NMR (DMSO, $\mathrm{A}_{2} \mathrm{X}$ spin sistemi):19.0 (ikili, $\mathrm{PCl}_{2}$ ), -12.04 (üçlü, $\left.\mathrm{P}\left(\mathrm{OOCCHCHC} \mathrm{H}_{4} \mathrm{Cl}\right)_{2}\right)$.

\subsubsection{Hekzaklorosiklotrifosfazen ile 4-kloro-fenil-asetik asidin tepkimesi}

Hekzaklorosiklotrifosfazenin $(0,25 \mathrm{~g} ; 0,730 \mathrm{mmol})$ ve trietilaminin $(1,25 \mathrm{~mL} ; 8,755$ mmol) THF(30 mL) deki çözeltisine 4-kloro-fenil-asetik asidin (1,88 g; 8,755 mmol) 5 $\mathrm{mL}$ THF çözeltisi yavaş yavaş ilave edildi. Tepkime oda şartlarında 72 saat devam ettirildikten sonra oluşan tuz süzülerek ayrıldı. Oluşan tuz oda şartlarında kurutuldu ve bu tuzun 1,96 g (teorik olarak iki mol klora karşılık trietiamonyum klorür miktarı:0,198 g) olduğu belirlendi. Çözeltideki karışım $\mathrm{CH}_{2} \mathrm{Cl}_{2} / \mathrm{n}$-hekzan(7/1) çözücü karışımında ince tabaka ve kolon kromatografileriyle saflaştırıldı. Saflaştırma işleminden sonra elde edilen beyaz kat1 bileşiğin 2,2-di-(4-kloro-feni-asetoiloksi)-4,4,6,6-tetra-klorosiklotrifosfazen(5) olduğu analiz sonuçlarında anlaşıldı (\%10, e.n.: $\left.132{ }^{\circ} \mathrm{C}\right)$. FTIR $\left(\mathrm{cm}^{-}\right.$ $\left.{ }^{1}\right)$ : 1728 ve 1721 ( $\operatorname{sim}$. ve asim $\left.\mathrm{C}=\mathrm{O}\right), 1238,1223,1188,1172(\mathrm{P}=\mathrm{N}), 1016(\mathrm{P}-\mathrm{OCO})$, 853(P=N-P), 584 ve 513 (P-Cl). ${ }^{1} \mathrm{H}$ NMR(DMSO-D); $\delta$ (ppm):7,30 (ikili), 7.20 (ikili), 2,45 $\left(-\mathrm{CH}_{2}\right.$ ) $, 3,50$ (DMSO içinde $\left.\mathbf{H}_{2} \mathrm{O}\right), 2.40$ (DMSO $\left.-\mathrm{CH}_{3}\right) .{ }^{13} \mathrm{C}$ NMR(DMSO-D; $\delta$ (ppm): 173,37 (C=O), 128,90, 128,66, 128,45, 128,36, 41,71 (- $\left.\mathrm{CH}_{2}-\right), 40,0$ (DMSO-D). ${ }^{31} \mathrm{P}$ NMR (DMSO-D; $\mathrm{A}_{2} \mathrm{X}$ spin sistemi):17,90 (ikili, $\mathrm{PCl}_{2}$ ), $-16,10$ (üçlü, $\left.\mathrm{P}\left(\mathrm{OOCCH}_{2} \mathrm{C}_{6} \mathrm{H}_{4} \mathrm{Cl}\right)_{2}\right)$.

\section{Sonuçlar ve tartışma}

Hekzaklorosiklotrifosfazen ile alifatik karboksilik asitler arasındaki tepkimenin oluştuğunu tepkime esnasında oluşan trietilamonyum klorürden $\left[\left(\mathrm{C}_{2} \mathrm{H}_{5}\right)_{3} \mathrm{NHCl}\right]$ ilk olarak anlaşıldı (Şekil 1). Bütün tepkimelerde oluşan bu tuzun miktarı 1,94 ile 1,99 g arasında olduğu belirlendi. Bu miktar, teorik olarak hesaplanan 2 mol klorün yer değiştirmesinde oluşan tuza karşılık geldiği belirlendi. Dolayısıyla, oluşan organosiklotrifosfazenin disubstitüe organosiklotrifosfazen olduğu gravmetrik tayin neticesinde anlaşıldı. IR ve NMR spekstroskopileri, elde edilen organosiklotrifosfazenlerin yapısının tayininde kullanıldı. Spektroskopik ve gravmetrik analizlere ait değerler deneysel bölümde her madde için yarı ayrı verildi. 


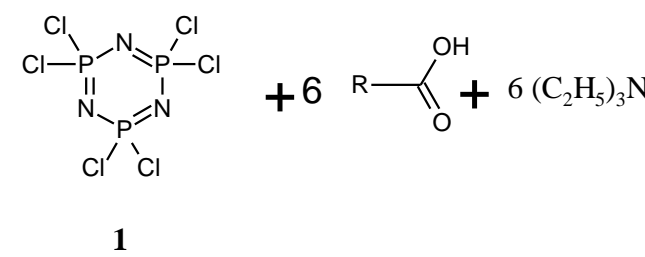

R: $\mathrm{H}_{3} \mathrm{C}-\underset{\mathrm{H}_{3} \mathrm{C}}{ } \widetilde{\sim}$ 2

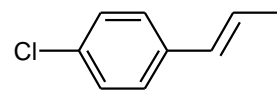

4

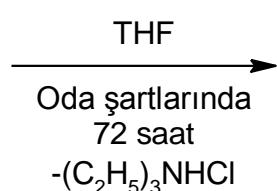

$-\left(\mathrm{C}_{2} \mathrm{H}_{5}\right)_{3} \mathrm{NHCl}$

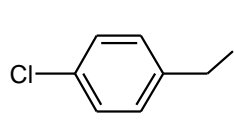

5<smiles>[R]C(=O)OC([R])=O</smiles>

2-5

Şekil 1. Hekzaklorosiklotrifosfazen ile alifatik karboksilik asitlerin tepkimesi.

Bileşiklerin IR spektrumunda, bileşiklerin yapısında karakteristik olan $\mathrm{C}=\mathrm{O}$ (sim ve Asim.), $\mathrm{P}=\mathrm{N}, \mathrm{P}-\mathrm{OOCAr}$ ve $\mathrm{P}-\mathrm{Cl}$ bağlarına ait pikler görüldü. $\mathrm{Bu}$ bağlara ait pikler sirasiyla $1740-1690,1240-1150,1040-1010$ ve $580-510 \mathrm{~cm}^{-1}$ arasındaki dalga sayısında olduğu belirlendi. Bütün bileşiklerin IR spektrumunda $\mathrm{P}-\mathrm{Cl}$ bağına ait piklerin görülmesinden, hekzaklorosiklotrifosfazendeki bütün klorların yer değiştirmediği anlaşıldı. Ayrıca, tepkime esnasında fosfazen yapısının da bozunmadığı bu spektrumdan belirlendi.

Bileşiklerin ${ }^{1} \mathrm{H}$ ve ${ }^{13} \mathrm{C}$ NMR spektrumundaki piklerin ve kimyasal kayma değerlerinin bileşiklerin için önerilen yapıya uygun olduğu anlaşıldı. Bileşiklerin ${ }^{1} \mathrm{H}$ NMR spektrumunda, proton pikleri fosfazen halkasına bağlanan organik yapıya uyun olarak görüldü (Şekil 1-5). Bileşik 2 ve 3 nin yapısında aromatik yapı olmadığı için alifatik proton pikleri 3 ile $1 \mathrm{ppm}$ arasında görülük iken bileşik 4 ve 5'in spektrumunda hem alifatik hem aromatik proton pikleri görüldü. Fakat, fosfazen halkasına bağlı olan organik grup sayısını belirlemek bu spektrumlardan mümkün olmadı. Bileşiklerin ${ }^{13} \mathrm{C} \mathrm{NMR}$ spketrumundaki pikler de organik yapıyla uyumlu olduğu anlaşıldı. Bileşiklerdeki karbonile ait pikin 165 ppm civarında çıktığg spektrumda görüldü. Bu spektrumdan da fosfazen halkasına bağlanan alifatik karboksilik asit sayısını belirlemek mümkün olmadı.

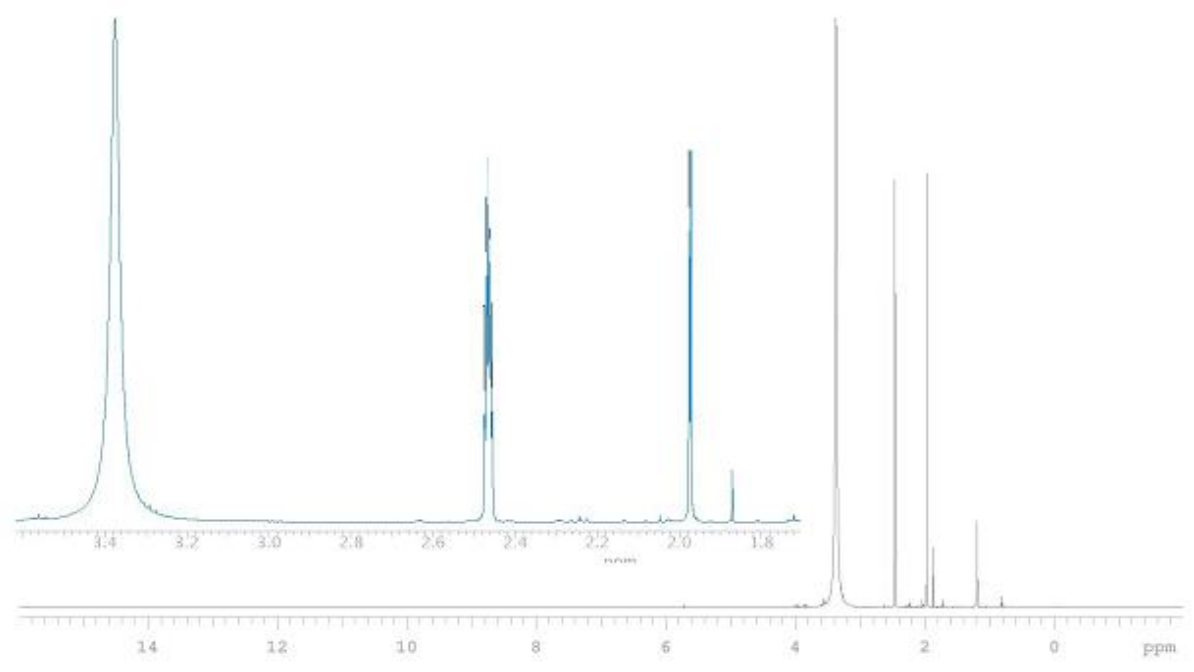

Şekil 2. Bileşik 2'nin ${ }^{1} \mathrm{H}$ NMR spektrumu. 


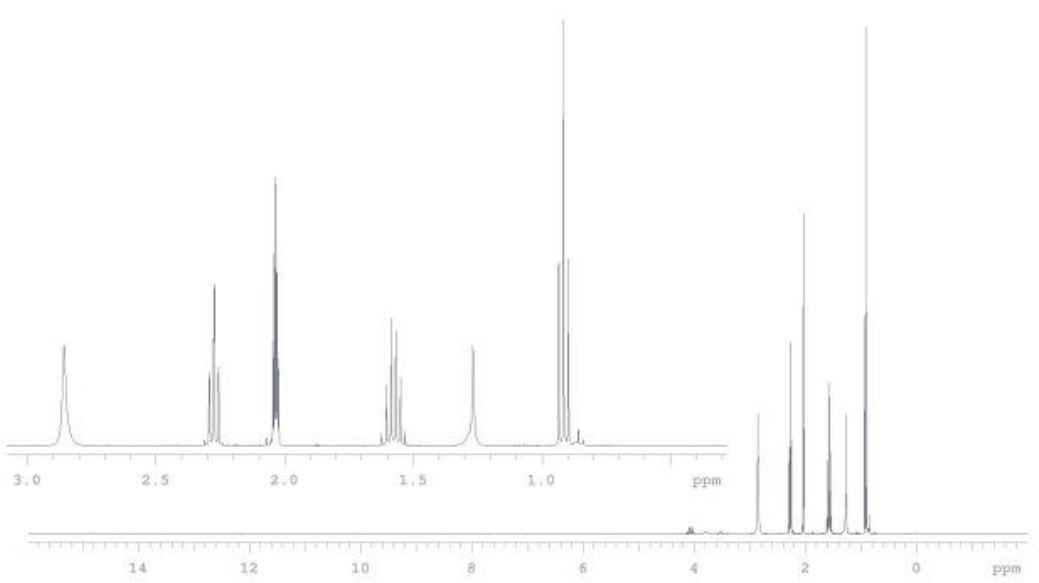

Şekil 3. Bileşik 3'ün ${ }^{1} \mathrm{H}$ NMR spektrumu.

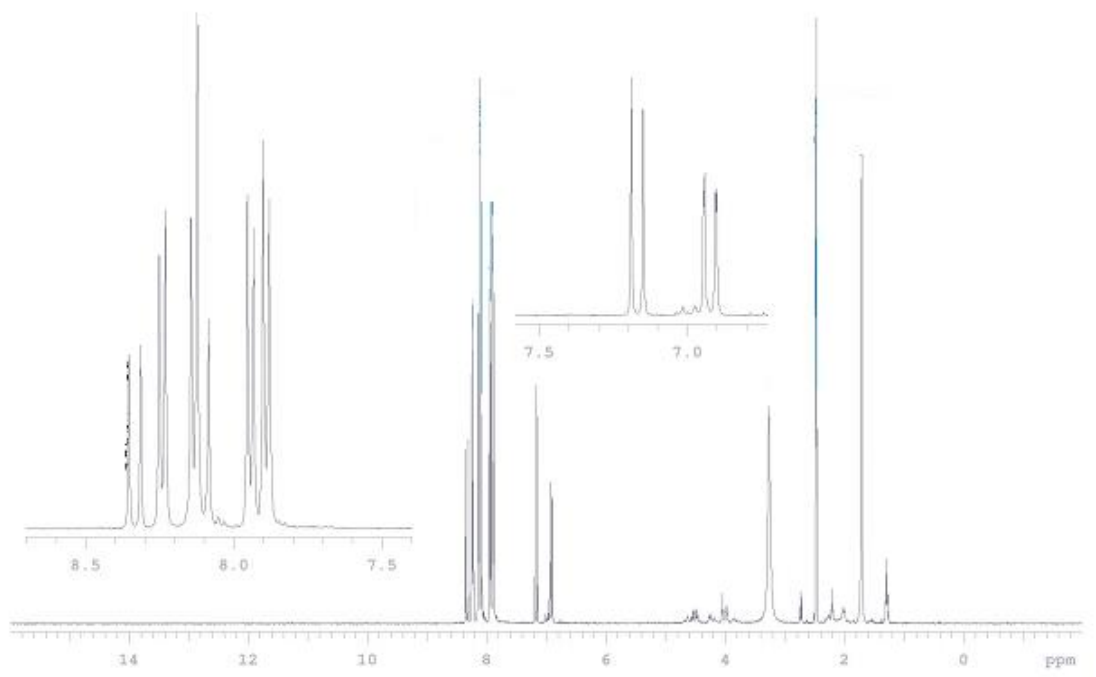

Şekil 4. Bileşik 4'ün ${ }^{1} \mathrm{H}$ NMR spektrumu.

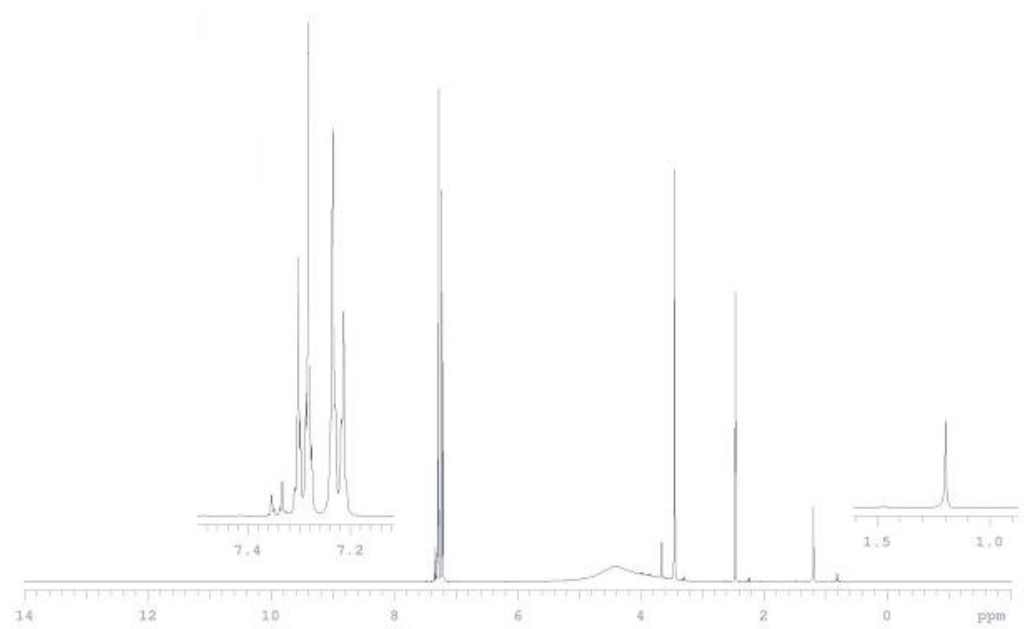

Şekil 5. Bileşik 5'in ${ }^{1} \mathrm{H}$ NMR spektrumu. 
Halkalı fosfazen bileşiklerin yapısının belirlenmesinde önemli analizlerden birisi de ${ }^{31} \mathrm{P}$ NMR spektrumudur. Bütün bileşiklerin ${ }^{31} \mathrm{P}$ NMR spektrumunda 20-15 ppm arasında ikili ve -10 ile -20 ppm arasında üçlü iki farklı pik görüldü (Şekil 6-9). Bu piklerden organofosfazenin mono substitüe veya geminal disubstiteü olduğu anlaşılmaktadır. Bu spektrum gravmetrik analiz sonucu ile birlikte değerlendirildiğinde, elde edilen bütün bileşiklerin (2-5) geminal disubstitüe olduğu anlaşıldı.

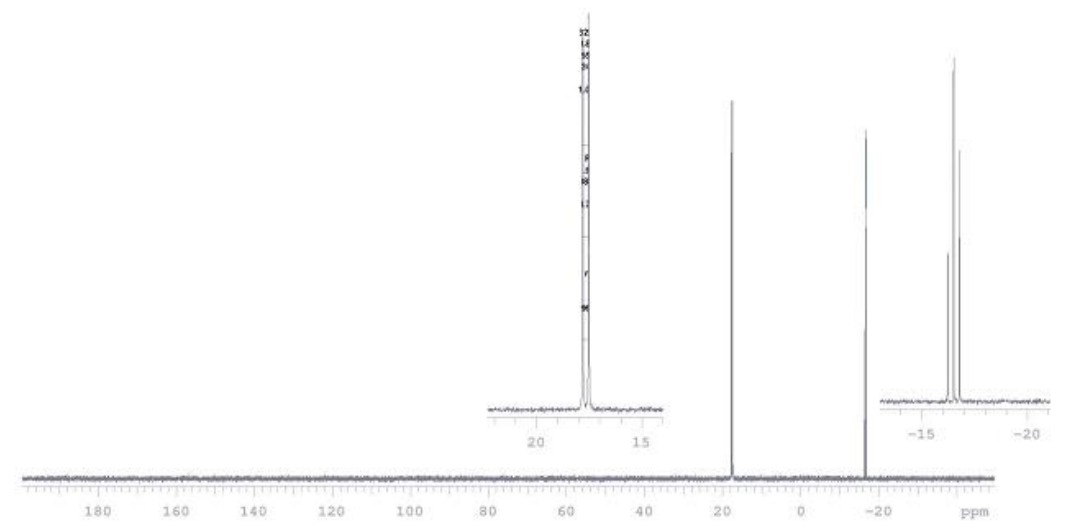

Şekil 6. Bileşik 2'nin ${ }^{31}$ P NMR spektrumu.

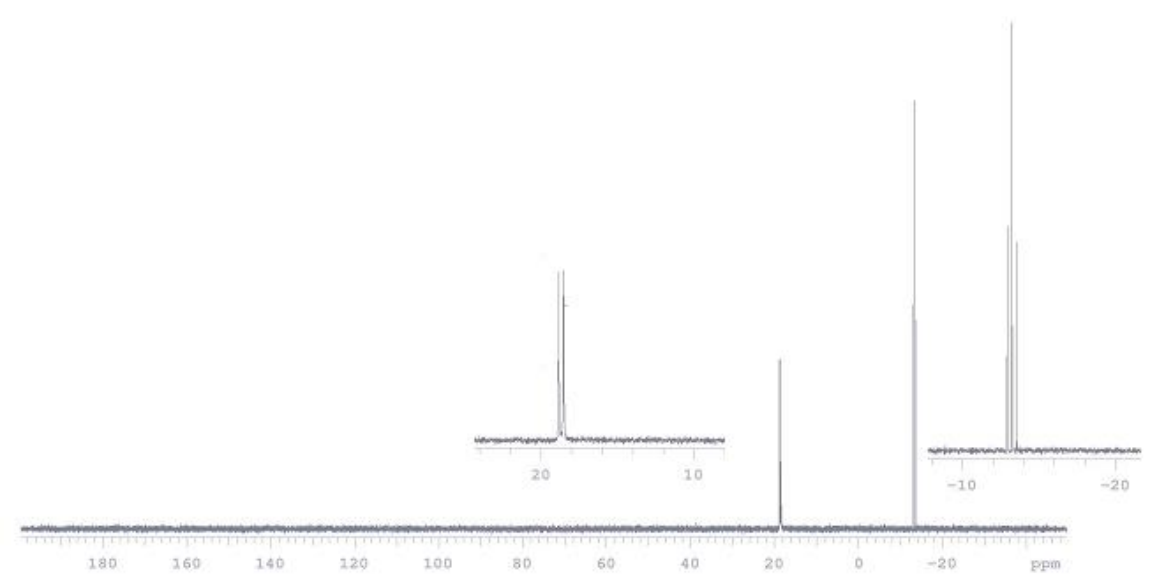

Şekil 7. Bileşik 3'ün ${ }^{31} \mathrm{P}$ NMR spektrumu.

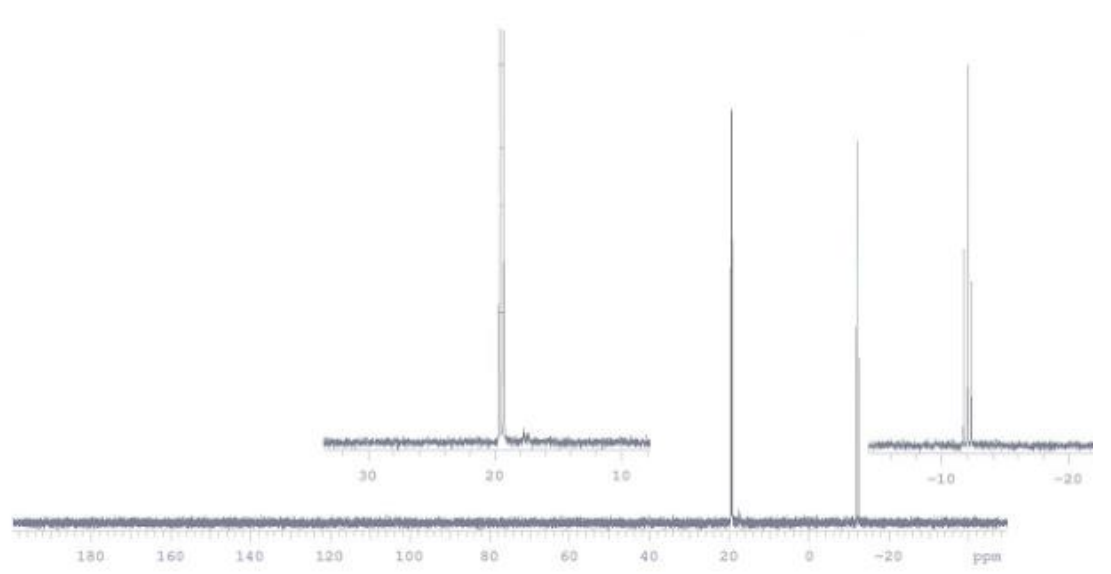

Şekil 8. Bileşik 4'ün ${ }^{31}$ P NMR spektrumu 


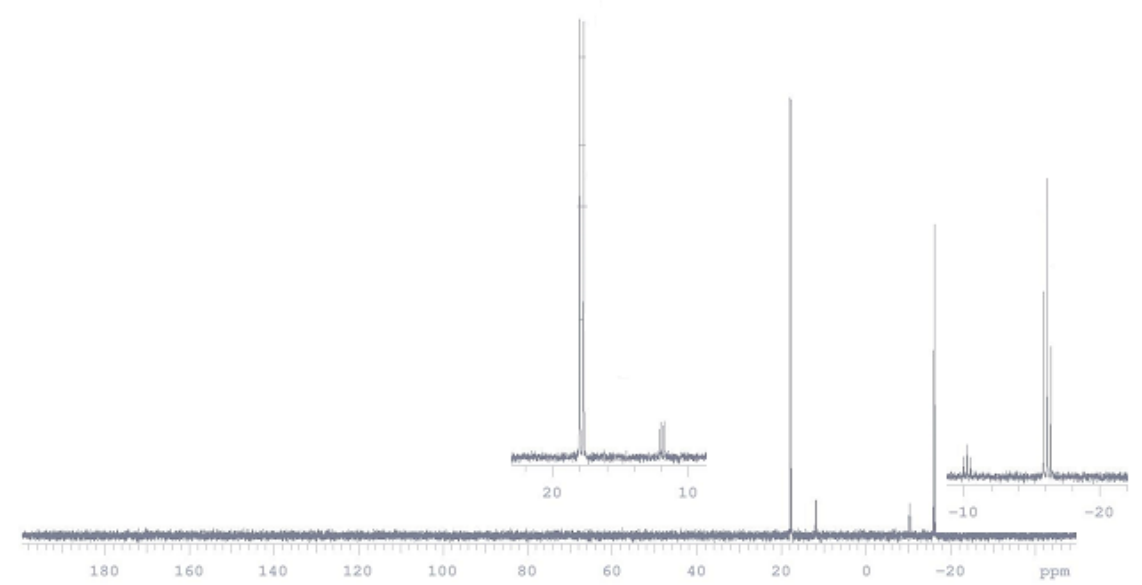

Şekil 9. Bileşik 5'in ${ }^{31}$ P NMR spektrumu

\section{Teșekkür}

Bu çalışmamız HÜBAK tarafından 14173 nolu proje ile desteklenmiştir.

\section{Kaynaklar}

[1] Aslan, F., Ozturk, A.I., Soylemez, B., Synthesis of fluorescence organocyclotriphosphazene derivatives having functional groups such as formyl, Schiff base and both formyl and Schiff base without using Ar or N-2 atmosphere, Journal of Molecular Structure, 1137, 387-395, (2017).

[2] Hanife, İ., Güzel, A., Yüksel, F., The reaction of hexachlorocyclotriphosphazatriene with p-aminophenol, Phosphorus, Sulfur, and Silicon and the Related Elements, 192, 92-97, (2017).

[3] Arslan, M., Aslan, F., Öztürk, A.I, Arylation reaction of N-dichlorophosphorylP-trichlorophosphazene, Heteroatom Chemistry, 14, 138-143, (2003).

[4] Allcock, H. R. Phosphorue-Nitrogen Compounds, Academic Press (New York and London), 279- 281, (1972).

[5] Bezman, I. I., Reed,W. R., Nitrile Formation by Reaction of Triphosphonitrilic Chloride with Carboxylic Acid Salts, Journal of the American Chemical Society, 82, 2167-2168, (1960).

[6] Caglioti, L., Poloni, M., Rosini, G., Phosphonitrilic Chloride as Activator of Carboxylic Acids. Formation of Amides and Hydrazides, The Journal of Organic Chemistry, 99, 2979-2981, (1968).

[7] Yokoyama, M., Cho, Y., Aida, R., Reactions of triphosphonitrilic chloride with carboxylic acids, Kgyo Kagaku Zasshi, 66, 609-613, (1963).

[8] Uslu, A., Balci, C., Yüksel, F., Özcan, E., Dural, S., Beşli, S., The investigation of thermosensitive properties of phosphazene derivatives bearing amino acid ester groups, Journal of Molecular Structure, 1136, 90-99, (2017). 